\title{
Seismic behavior of composite walls of sludge ceramsite foamed concrete block
}

\author{
Min Zhang ${ }^{1, a}$, Wei Huang ${ }^{1}$, Xinwei Miao ${ }^{1}$, Zengke Yang $^{1}$ and Rongrong $\mathrm{Hu}^{2}$ \\ ${ }^{1}$ College of Civil Engineering, Xi'an University of Architecture and Technology,Xi'an, Shaanxi Province 710055, \\ China, E-mail: qqhuangwei2005@126.com \\ ${ }^{2}$ College of Architecture, Xi'an University of Architecture and Technology,Xi'an, Shaanxi Province 710055, China \\ E-mail:596216891@qq.com
}

\begin{abstract}
In order to study the seismic behavior of the composite wall of sludge ceramsite foamed concrete block, two specimens with reinforcing rib in U-shape block under cyclic loads are studied in the paper. Based on the experiment, the damage process, failure mechanism, hysteresis curves, initial stiffness, stiffness degradation and energy dissipation are discussed. Test results indicate that the composite wall of sludge ceramsite foamed concrete went through three stages: elastic stage, elastoplastic stage, failure stage, and the failure mechanism is reasonable; both of the two specimens have good ductility and energy dissipation capacity, and the increasing of reinforcing rib can effectively improve the seismic performance of wall. Whereas, in addition to the set of reinforcing rib itself, the mutual coupling action between blocks, reinforcing ribs and boundary elements may be a factor affects the seismic behavior of the $\mathrm{CW}$. And, the practical application of the $\mathrm{CW}$ should be further compared and investigated. Keywords: composite wall, sludge ceramsite foamed concrete, seismic behavior.
\end{abstract}

\section{Guidelines}

Sludge generated from wastewater treatment plants represent a potentially harmful solid waste threatens to human health and environment. The amount of sludge is continuously increasing with due to the growth of urbanization in China. Sludge is characterized with high moisture content, huge volume, poor mechanic properties is therefore difficult to be stored and transported. Moreover, combined with a substantial amount of toxic component contains; the sludge poses a threat as a secondary pollution if not handled properly [1-3].

In recent years, studies on the sludge ceramsite, recycled aggregate, foamed concrete, and masonry and their practical application have been carried out, demonstrating that the recycled materials are suitable for residential construction industry architecture with advantages of energy-saving, environmental protection and low cost [4-10].

Based on the above, a new composite wall of sludge ceramsite foamed concrete block, i.e. the CW, is proposed [11-13]. The composite wall structure is composed of wallboard consist of sludge ceramsite foamed concrete block and reinforcing rib in U-shape block, cast-in-situ boundary elements, and the floor.

${ }^{a}$ Corresponding author : mzhangsjz528@163.com 


\section{Materials and methods}

\subsection{Materials}

In this study, the mix proportion of sludge ceramsite foamed concrete is shown in Table 1. The fine aggregate is medium sand, the cement is P.O42.5 ordinary Portland cement, the fly-ash is 2-level flyash, the size of sludge ceramsite is $6-12 \mathrm{~mm}$, and the apparent density of sludge ceramsite is 880 $\mathrm{Kg} / \mathrm{m}^{3}$.

Table 1. Mix proportions.

\begin{tabular}{cccccc}
\hline $\begin{array}{c}\text { Fine } \\
\text { aggregate } \\
\mathrm{Kg} / \mathrm{m}^{3}\end{array}$ & $\begin{array}{c}\text { Ceme } \\
\mathrm{nt} \\
\mathrm{Kg} / \mathrm{m}^{3}\end{array}$ & $\begin{array}{c}\text { Fly- } \\
\text { ash } \\
\mathrm{Kg} / \mathrm{m}^{3}\end{array}$ & $\begin{array}{c}\text { Sludge } \\
\text { ceramsite } \\
\mathrm{Kg} / \mathrm{m}^{3}\end{array}$ & $\begin{array}{c}\text { Foaming agent } \\
\text { (by volume of } \\
\text { water)\% }\end{array}$ & $\begin{array}{c}\text { w/ } \\
\mathrm{c}\end{array}$ \\
\hline 641 & 256 & 256 & 289 & 2 & 0.5 \\
\hline
\end{tabular}

Several cubes of $150 \mathrm{~mm}$ side length were prepared and cured in the laboratory in a water bath under a temperature of $20^{\circ} \pm 2^{\circ} \mathrm{C}$ and then tested at the age of 28 days for compressive strength and tensile splitting strength. The average of three values was recorded as the strengths of concrete.

Several standard prisms of $150 \mathrm{~mm} \times 150 \mathrm{~mm} \times 150 \mathrm{~mm}$ were prepared and cured in the laboratory in a water bath under a temperature of $20^{\circ} \pm 2^{\circ} \mathrm{C}$ and then tested at the age of 28 days for axial compressive strength. The average of three values was recorded as the strengths of concrete.

Normal concrete cubes and prisms were prepared and tested under the same conditions as sludge ceramsite foamed concrete.

The mechanical properties of the sludge ceramsite foamed concrete (SFC) and normal concrete (NC) are shown in Table 2. And the uniaxial compression stress-strain carves of sludge ceramsite foamed concrete are shown in Fig. 1.

Table 2. Mechanical properties of concrete.

\begin{tabular}{cccc}
\hline Concrete & $\begin{array}{c}\text { Volume weight } \\
\mathrm{Kg} / \mathrm{m}^{3}\end{array}$ & $\begin{array}{c}\text { Cube crushing } \\
\text { strength } \\
\mathrm{MPa}\end{array}$ & $\begin{array}{c}\text { Axial compressive } \\
\text { strength } \\
\mathrm{MPa}\end{array}$ \\
\hline SFC & 15.3 & 16.7 & 10.3 \\
$\mathrm{NC}$ & 25.6 & 29.5 & 25.1 \\
\hline
\end{tabular}

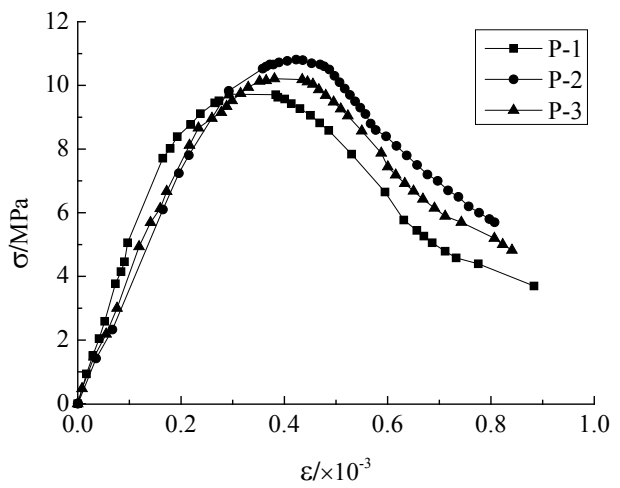

Figure 1. Stress-train curves of SFC. 


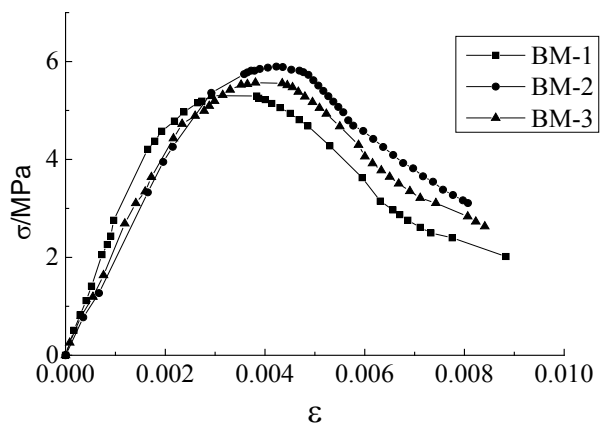

Figure 2. Stress-strain carves of block masonry.

Several specimens of sludge ceramsite foamed concrete block masonry were prepared and tested for axial compressive strength and shear strength of masonry. The average of three values was recorded as the strengths of concrete.

The test results of the masonry are shown in Table 3. And the uniaxial compression stress-strain carves of masonry are shown in Fig. 2.

Table 3. Mechanical properties of block masonry.

\begin{tabular}{ccc}
\hline $\begin{array}{c}\text { Compressive strength } \\
\mathrm{MPa}\end{array}$ & $\begin{array}{c}\text { Shear strength } \\
\mathrm{MPa}\end{array}$ & $\begin{array}{c}\text { Elastic modulus } \\
\mathrm{MPa}\end{array}$ \\
\hline 6.15 & 0.067 & 4040 \\
\hline
\end{tabular}

The mechanical properties of reinforcement are shown in Table 4.

Table 4. Mechanical properties of reinforcement.

\begin{tabular}{lccc}
\hline Type & $\begin{array}{c}\text { Yield strength } \\
\mathrm{MPa}\end{array}$ & $\begin{array}{c}\text { Ultimate strength } \\
\mathrm{MPa}\end{array}$ & $\begin{array}{c}\text { Elastic modulus } \\
\mathrm{MPa}\end{array}$ \\
\hline D2 & 374.7 & 407.1 & $1.95 \times 10^{5}$ \\
D4 & 672.5 & 793.3 & $2.10 \times 10^{5}$ \\
D6 & 550.6 & 623.3 & $2.10 \times 10^{5}$ \\
\hline
\end{tabular}

\subsection{Specimens}

In this study, the fine aggregate is medium sand, the cement is P.O42.5 ordinary Portland cement, the fly-ash is 2-level fly-ash, the size of sludge ceramsite is $6-12 \mathrm{~mm}$, and the apparent density of sludge ceramsite is $880 \mathrm{Kg} / \mathrm{m}^{3}$.In this study, two $1 / 2$-scale $\mathrm{CW}$ specimens with a height to length ration of 1.14 were designed and tested under quasi-static cyclic loading. This research aimed at evaluating the seismic behavior of the new ecological composite wall and giving design suggestions. In this study, effect of different set of ribbed beam on the crack patterns and failure modes, peak load, drift capacity, stiffness degradation, and energy dissipation are compared and analyzed, respectively.

Two CW specimens were tested to provide information on shear strength and drift capacity of prefabricated shear wall, and to evaluate shear requirements specified by Chinese code for design of concrete structures GB50010-2010 [14] and Chinese code for design of masonry structures DB50003$2011[15]$.

All specimens have a length of $1400 \mathrm{~mm}$ and a height of $1600 \mathrm{~mm}$, and a thickness of $120 \mathrm{~mm}$. The height from wall base to the action point of lateral loading is $1500 \mathrm{~mm}$.

The ribbed beam of all specimens wallboard was vertically reinforced with four hot rolled plain bars D4 (diameter $=4 \mathrm{~mm}$, shown in Figure 2 as 4D4), and all ribbed beams were transversely reinforced with hot rolled plain bars D2 hoops and ties spaced at $60 \mathrm{~mm}$ (D2@60). Four hot rolled ribbed bars D6 (4D6) were used as the vertical reinforcement of the boundary of specimens CW-1 and $\mathrm{CW}-2$, constituting a longitudinal reinforcement ratio $\rho$ of $0.79 \%$. 


\subsection{Methods}

The horizontal load was applied on the specimens by a double-acting actuator with a capacity of 1000 $\mathrm{kN}$. The axial load was applied with a hydraulic jack on the steel beam which was placed on the top of the RC coupling beam. The steel beam was used to make sure that the axial load was applied uniformly to the wall.

The axial load remained constant when the specimens were tested under cyclic lateral load. Force control was taken with the increasing amplitude of $10 \mathrm{kN}$, and for each load level one cycle was applied. After that, displacement control was conducted. The ductility level was $2 \mathrm{~mm}$ per amplitude, and for each ductility level three cycles were applied.

\section{Results and discussions}

\subsection{Damage process}

The axial load was applied first, and remained constant when the specimens were tested under cyclic lateral load. In specimen CW-1, initial cracking at the block interface was observed at load stage of $45 \mathrm{kN}$, corresponding to a rotational angle of about $0.0005 \mathrm{rad}$. At load stage of $58.8 \mathrm{kN}$, a long diagonal crack was observed at the surface of the block, which was defined as cracking state. Afterwards, corner to corner cracks were observed at the block, and horizontal cracks located at the edge of block extended to the surface of ribbed beams. At a rotational angle of about $0.009 \mathrm{rad}$, the peak load was achieved, which was defined as peak state. After that, numerous cracks were observed, and cracks located at the wallboard-boundary element interface of extended from ribbed columns to boundary elements. At the rotational angle of about $0.015 \mathrm{rad}$, a noticeable crushing of concrete at the bottom of boundary element was observed, which was defined as the failure state. The failure process of specimens CW-2 was similar to specimen CW-1. However, a lower cracking load of $50.9 \mathrm{kN}$ and a lager peak load of $117.9 \mathrm{kN}$, were achieved in specimen $\mathrm{CW}-2$, due to the different the set of reinforcing rib reinforcement. Furthermore, during the whole process of the experiment, no collapse phenomenon was observed.

\subsection{Crack patterns and failure modes.}

The CW specimens are prone to fail in a mixed flexure-shear or shear mode. For evaluating the observed wall behavior, two failure modes were identified [16]. The first mode is mixed flexure-shear, characterized by resisting shear force by aggregate interlock in the compression zone and boundary elements. The second mode is diagonal compression failure, characterized by yielding of some steel bars and noticeable web crushing of SFC block. The final crack patterns of specimens are shown in Fig. 3. Failure mode of specimen $\mathrm{CW}-2$ was a mixed flexure-shear failure whereas diagonal compression failure mode was observed in specimen $\mathrm{CW}-1$.

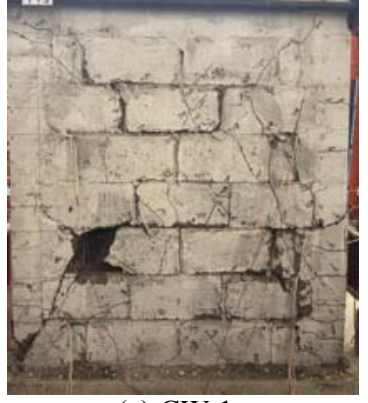

(a) $\mathrm{CW}-1$



(b) $\mathrm{CW}-2$

Figure 3. Crack patterns of specimens at failure load. 


\subsection{Parameters of response measured on specimens}

Based on the above introduced hysteresis curves, some useful performance indexes are introduced. Drift at cracking, IDcr, is the ratio between the cracking displacement, $\delta \mathrm{cr}$, and the height of wall, $\mathrm{H}$, which is expressed as IDcr $=\delta \mathrm{cr} / \mathrm{H}$. Similarly, IDy, IDp and IDu are associated to displacement corresponds to yielding force, $\delta \mathrm{y}$, displacement corresponds to peak force, $\delta \mathrm{p}$, and ultimate displacement, $\delta \mathrm{u}$. Ductility, $\mu$, is the ratio between the ultimate displacement, $\delta \mathrm{u}$, and the yielding force, $\delta y$. The parameters measured during tests of specimens are summarized in Table 5.

In general, specimen CW-2 exhibited larger peak force than specimen CW-1, which means the increasing of reinforcement rib has an influence on increasing the bearing capacity. Whereas compared with specimen CW-1, specimens CW-2 exhibited larger force values, except cracking force, but smaller drift ratios and ductility, which show that the increasing of reinforcing rib made the wallboard and boundary elements work as one unit. Although specimen CW-1 got a higher drift ratios and ductility, lower force values because of the sliding of the slurry sitting between the blocks were observed.

Table 5. Main parameters of response measured on specimens.

\begin{tabular}{|c|c|c|c|c|c|c|c|c|c|}
\hline \multirow[b]{2}{*}{ No. } & \multicolumn{2}{|c|}{ Cracking state } & \multicolumn{2}{|c|}{ Yielding state } & \multicolumn{2}{|c|}{ Peak state } & \multicolumn{2}{|c|}{ Failure state } & \multirow[b]{2}{*}{$\mu$} \\
\hline & $\begin{array}{cc}F_{\mathrm{cr}} & \delta_{\mathrm{cr}} \\
\mathrm{kN} & \mathrm{mm}\end{array}$ & $\begin{array}{c}I D_{\text {cr }} \\
\%\end{array}$ & $\begin{array}{cc}F_{\mathrm{y}} & \delta_{\mathrm{y}} \\
\mathrm{kN} & \mathrm{mm}\end{array}$ & $\begin{array}{c}I D_{\mathrm{y}} \\
\%\end{array}$ & $\begin{array}{cc}F_{\mathrm{p}} & \delta_{\mathrm{p}} \\
\mathrm{kN} & \mathrm{mm}\end{array}$ & $\begin{array}{c}I D_{\mathrm{p}} \\
\%\end{array}$ & $\begin{array}{cc}F_{\mathrm{u}} & \delta_{\mathrm{u}} \\
\mathrm{kN} & \mathrm{mm} \\
\end{array}$ & $\begin{array}{c}I D_{\mathrm{u}} \\
\%\end{array}$ & \\
\hline CW-1 & 58.81 .2 & 0.08 & 72.32 .7 & 0.18 & 98.014 .0 & 0.93 & 82.423 .1 & 1.54 & 8.6 \\
\hline CW-2 & 50.91 .1 & 0.07 & 99.63 .3 & 0.22 & 117.98 .0 & 0.53 & 100.417 .0 & 1.13 & 5.2 \\
\hline
\end{tabular}

\section{Conclusions}

An experimental study that comprised quasi-static cyclic tests of two composite walls were conducted to provide information on seismic performance of walls in terms of crack patterns and failure modes, hysteresis curves, initial stiffness, stiffness degradation and energy dissipation. The main results obtained from the tests can be summarized as follows.

-Failure mode of specimen CW-2 was a mixed flexure-shear failure whereas diagonal compression failure was observed in specimen CW-1.

- The set of reinforcing rib has influence on the peak load, and the CW specimens show a high load carrying capacity and energy dissipation capacity based on a rational design, and the results can provide support for practical applications in composite wall structure system..

- Compared with the specimen CW-1, specimen CW-2 shows a better seismic behavior and higher shear capacity. Whereas, in addition to the set of reinforcing rib itself, the mutual coupling action between blocks, reinforcing ribs and boundary elements may be a factor affects the seismic behavior of the $\mathrm{CW}$. And, the practical application of the $\mathrm{CW}$ should be further compared and investigated.

\section{Acknowledgments}

The authors gratefully acknowledge the financial support provided by the National Natural Science Foundation of China (51378416\&51378410).

\section{References}

1. M. Ren, X. J. Lu and X. Y. Wang, China Resources Comprehensive Utilization, vol.26, no.2, pp.19-21, 2008.(In Chinese)

2. L. David, F. Johann and H. B. Paul, Science of the Total Environment, vol. 407, pp.36743680(2009)

3. X. Liu, Y. H. Ye, Z. J. Wang et al., Sichuan Building Science, vol. 37, no. 6, pp. 81-84,2011.(In 
Chinese)

4. J. H. Tay and K. Y. Show, Water Science and Technology, vol. 36, no. 11, pp. 259-266(1997)

5. J. H. Tay and K. Y. Show and S. Y. Hong, Journal of Materials in Civil Engineering, vol. 9, no.11, pp. 392-398(2002)

6. G. L. Abdul, I. Azni, A. S. Abdul et al., Journal of Material Cycles and Waste Management, vol.6, no. 1, pp. 41-47(2004)

7. M. Ignacio, F. A. Luis and R. Fernando, Waste Management, vol. 27, no. 12, pp. 1829-1844(2007)

8. M. M. Jordan, M. B. Almendro-Candel and M. Romero, Applied Clay Science, vol. 30, pp. 219224(2005)

9. G. Q. Liu, C. X. Shi and W. R. Lv, Journal of Building Structures, vol. 26, no. 5, pp. 8190(2005)(In Chinese)

10. X. M. Zhai and H. B. Jiang, Journal of Harbin Institute of Technology, vol. 40, no. 2, pp. 187191(2008)(In Chinese)

11. Y. J. Shao, X. J. Xie, Z.W. Yin et al., Concrete, no. 11, pp. 95-97(2007)

12. J. Z. Xiao, J. D. Huang and Y. YAO, Journal of Building Structures, vol. 33, no. 2, pp. 100109(2012)(In Chinese)

13. P. Liu, Q. Yuan, M. Guo et al., Journal of Central South University (Science and Technology), vol. 43, no. 3, pp. 1107-1113(2012)(In Chinese)

14. GB, "Code for design of concrete structures," GB50010-2010, China Architecture \& Building Press(2010)(In Chinese)

15. GB, "Code for Design of Masonry Structures," GB50003-2011, China Architecture \& Building Press(2011)(In Chinese)

16. J. Carrillo, J. M. Lizarazo and R. Bonett, Engineering Structures, vol.93, pp.61-69(2015) 